\title{
ОЦЕНКА ЭФФЕКТИВНОСТИ ИСПОЛЬЗОВАНИЯ ПАРОГАЗОВЫХ ПРОДУКТОВ ПИРОЛИЗА ДРЕВЕСНЫХ ОТХОДОВ В КАЧЕСТВЕ РАБОЧЕГО ТЕЛА В ГАЗОТУРБИННЫХ УСТАНОВКАХ И ДВИГАТЕЛЯХ ВНУТРЕННЕГО СГОРАНИЯ
}

\author{
Цибульский Святослав Анатольевич1, \\ stzibulsky@tpu.ru
}

\section{Ларионов Кирилл Борисович1,} laryk070@gmail.com

\section{Слюсарский Константин Витальевич1, slyuskonst@gmail.com}

\author{
Галашов Николай Никитович1, \\ gal@tpu.ru
}

Гаспарян Гарик Давидович ${ }^{2}$ garik.gasparian@yandex.ru

\author{
Улько Александр Анатольевич2, \\ ulkoalexandr@gmail.ru \\ 1 Национальный исследовательский Томский политехнический университет, \\ Россия, 634050, г. Томск, пр. Ленина, 30. \\ 2000 «Сибирский Биоуголь», \\ Россия, 248000, г. Калуга, ул. Воскресенская, 33
}

\begin{abstract}
Актуальность темы обусловлена возможностью использования такого вида топлива, как парогазовые продукты пиролиза древесных отходов, в качестве основного или вспомогательного топлива для выработки электрической энергии. Направления, связанные со снижением углеродных выбросов, позволят расширить области применения пиролиза как средства переработки промышленных отходов, сводя к минимуму их воздействие на окружающую среду.

Цель: исследование вопросов повьшения эфффективности выработки электрической энергии на двигателях внутреннего сгорания и газотурбинных установках при работе на продуктах пиролиза древесных отходов с целью сокращения потребления невозобновляемых энергоресурсов, таких как уголь, нефрть и природньй газ.

объекты: установка пиролиза древесных отходов, двигатели внутреннего сгорания и газотурбинные установки, работающие на парогазовых продуктах пиролиза древесных отходов.

Методы: численные методы исследования на основе математического моделирования систем и элементов двигателей внутреннего сгорания и газотурбинных установок на основе материальных и энергетических балансов.

Результаты. Разработана математическая модель и программа для теплового расчета двигателей внутреннего сгорания и газотурбинных установок, сжигающих парогазовые продукты пиролиза. Проведен параметрический анализ влияния температуры выхода парогазовых продуктов из пиролизной установки на эфффективность работы, электрическую мощность и температуру уходящих газов рассмотренных силовых агрегатов. Установлено, что для утилизации парогазовых продуктов пиролиза с целью получения электрической энергии наиболее эффрективно применение двигателя внутреннего сгорания, работающего по термодинамическому циклу Тринклера, и газотурбинной установки, работающей по термодинамическому ииклу Брайтона, при этом абсолютный электрический коэффрициент полезного действия в номинальном режиме работы пиролизной установки составляет 23,34 и 22,28 \% соответственно. Выявлено, что при использовании парогазовых продуктов пиролиза в качестве вспомогательного топлива к метану в объемной составляющей 25 \%, снижение мощности силового агрегата ожидается не более $10 \%$.
\end{abstract}

\section{Ключевые слова:}

Пиролиз, парогазовые продукты, термодинамический цикл, двигатель внутреннего сгорания, газотурбинная установка, математическая модель.

\section{Введение}

В настоящее время одним из потенциальных решений, связанных со снижением углеродного следа энергетических и металлургических предприятий, является использование углерод-нейтрального топлива в виде древесного угля - полукокса $[1,2]$. Это связано с тем, что образующийся при сжигании данного вида топлива $\mathrm{CO}_{2}$ был в обозримом прошлом поглощен из атмосферы, делая данные топлива т. н. углерод-нейтральными [3].
Одним из современных способов получения полукокса является технология медленного пиролиза биомассы, преобразование которой протекает в бескислородной среде при температуре $400-600{ }^{\circ} \mathrm{C}$ со скоростью нагрева 5-80 ${ }^{\circ} \mathrm{C}$ в минуту [4-6]. Основным продуктом медленного пиролиза является полукокс, характеризующийся низким содержанием золы, отсутствием серы и теплотой сгорания $\mathrm{Q}_{\mathrm{i}}^{\mathrm{r}}=28-33 \mathrm{MДж/кг} \mathrm{[4]}$ в зависимости от технологических параметров про- 
цесса и используемого сырья [5]. Вторичными продуктами являются биомасло и неконденсируемый газ, которые могут быть использованы в качестве вторичных энергоносителей для частичной компенсации энергозатрат непосредственно процесса пиролиза.

Биомасло, несмотря на высокий энергетический потенциал $\left(\mathrm{Q}_{\mathrm{i}}^{\mathrm{r}}=15-25 \mathrm{MДж/кг)}\right.$ [7], имеет ряд технологических особенностей, осложняющих его использование в энергетической отрасли [7]. Прежде всего, это связано с низким значением рН (2-3) [8], неоднородным физико-химическим составом [7] и высоким содержанием воды (15-30 \%) [7]. Повышенное содержание воды вызвано сложностью выбора правильного технологического режима конденсации парогазовой смеси и природой используемого сырья (биомассы), в частности наличия в ней связной влаги [9]. Это негативно отражается на его теплоте сгорания, сложности воспламенения, снижении температуры горения и может привести к преждевременному испарению и, как следствие, затруднению распыла масла в форсуночных устройствах топливной системы [10]. Таким образом, наличие представленных выше негативных технологических факторов снижает рыночный интерес к энергоносителям данного вида, делая его менее востребованным по сравнению с производимым полукоксом.

Наиболее удобным и эффективным способом подвода тепла к сырью является электрический нагрев ввиду аллотермического режима работы большинства пиролизных установок [11]. Нагрев с помощью ТЭНов позволяет обеспечить оперативное изменение режима работы пиролизной установки (регулирование скорости нагрева и температуры греющей среды) и технических характеристик получаемых продуктов.

Таким образом, одним из решений для использования вторичных энергоносителей является их сжигание в камерах сгорания газотурбинных установок (ГТУ) или двигателях внутреннего сгорания (ДВС) в виде парогазовой смеси для выработки электрической энергии.
Это позволит частично компенсировать энергозатраты на работу пиролизной установки и ее вспомогательных систем и дополнительно снизить или даже исключить накопление биомасла в случае отсутствия рыночного интереса к настоящему продукту.

Большинство существующих работ в области генерации электрической энергии посредством применения продуктов пиролизных технологий связаны с использованием жидких углеводородов, полученных в процессе переработки различных видов отходов (пластики, изношенные шины, биомасса) [12-15]. Таким образом, рабочим телом в ГТУ и ДВС являются парогазовые продукты пиролиза (ППП) жидких углеводородов.

В работах $[16,17]$ представлены результаты исследования использования пиролизных масел, полученных из пластиковых отходов и автомобильных шин, в качестве замены дизельному топливу в ДВС. Авторами рассмотрены вопросы впрыска парогазовых продуктов пиролиза с помощью форсунок высокого давления без существенных изменений их конструкции и характеристик горения в камере сгорания.

В настоящей работе приведены результаты численной оценки эффективности работы различных циклов ГТУ и ДВС при использовании парогазовых продуктов пиролиза древесных отходов в качестве основного или вспомогательного энергоносителя.

\section{Установка пиролиза древесных отходов}

Состав парогазовых продуктов пиролиза и материальный баланс получаемых продуктов пиролиза были определены по результатам опытных измерений, выполненных на установке медленного пиролиза древесных брикетов, размещенной на производственной площадке компании ООО «Сибирский Биоуголь» (п. Беляй, Томская область, Россия). На рис. 1 представлена принципиальная схема работы установки пиролиза древесных отходов непрерывного действия с получением брикетированного полукокса.

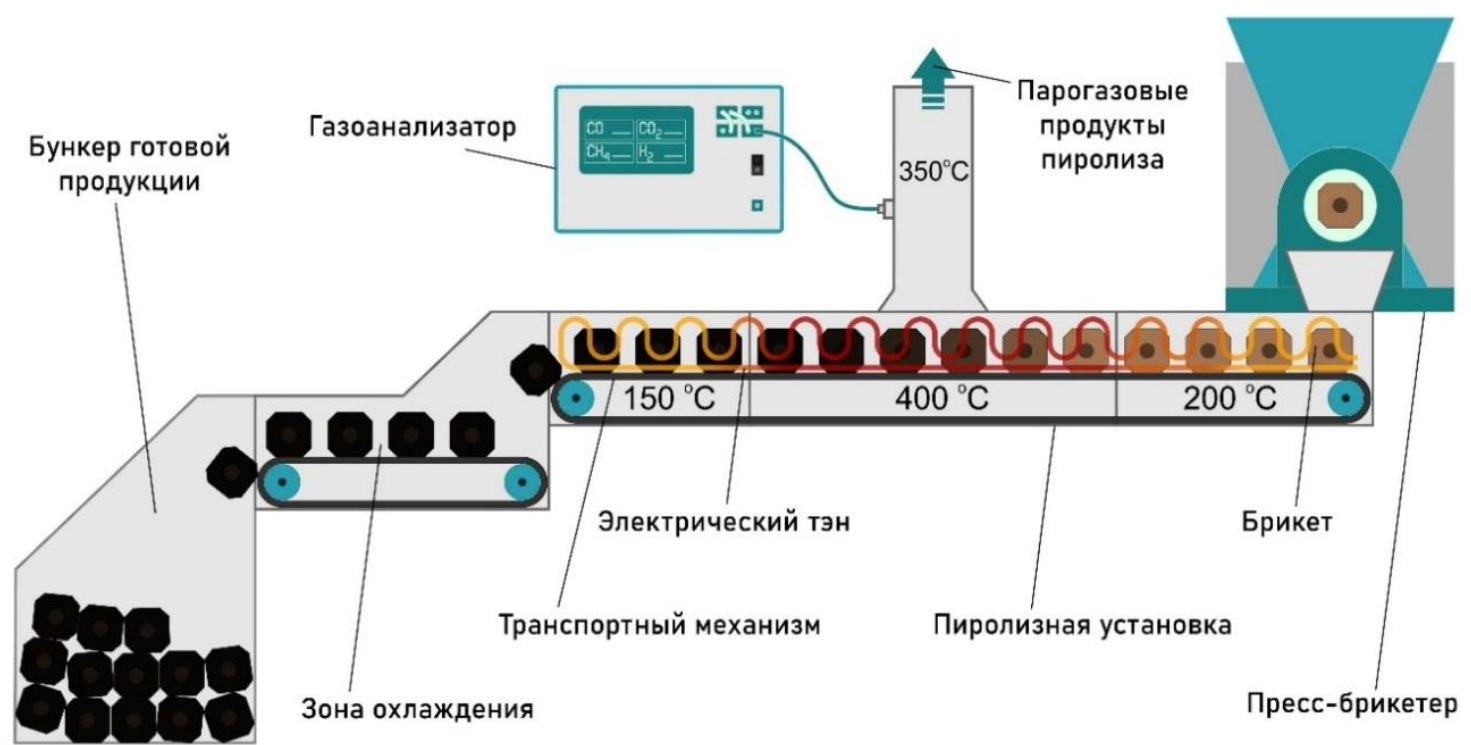

Рис. 1. Принципиальная схема установки пиролиза

Fig. 1. Basic diagram of pyrolysis installation 
Принцип работы установки заключается в проведении стадийного процесса пиролиза древесных брикетов с последовательным нагревом/охлаждением продуктов. Перед попаданием в пиролизную установку древесные отходы (сосновые опилки с рабочей влажностью около 10 мас. \%) брикетируются с помощью термического пресса при температуре $230 \pm 10{ }^{\circ} \mathrm{C}$. Далее брикеты поступают на металлизированную конвейерную ленту и транспортируются в первую часть камеры пиролизной установки, где подвергаются нагреву до температуры $200 \pm 20{ }^{\circ} \mathrm{C}$. Затем следует стадия нагрева до температуры $400 \pm 20^{\circ} \mathrm{C}$. Самая продолжительная стадия пиролизного процесса протекает при температуре $400{ }^{\circ} \mathrm{C}$. Завершающие стадии процесса связаны с охлаждением образующегося полукокса. Производительность пиролизной установки составляет 500 кг/ч (по исходному сырью). Подвод тепла к сырью осуществляется косвенным способом с помощью электрических нагревателей.

Таблица. Характеристики сырья и получаемых продуктов пиролиза

Table. $\quad$ Characteristic of raw materials and obtained pyrolysis products

\begin{tabular}{|c|c|}
\hline $\begin{array}{l}\text { Параметр } \\
\text { Argument } \\
\end{array}$ & $\begin{array}{c}\text { Значение } \\
\text { Value }\end{array}$ \\
\hline \multicolumn{2}{|c|}{$\begin{array}{l}\text { Технический состав, мac. \% } \\
\text { Technical composition, wt. \% }\end{array}$} \\
\hline $\begin{array}{l}\text { Влажность } \mathrm{W}^{\mathrm{r}} \\
\text { Humidity } \mathrm{W}^{\mathrm{r}}\end{array}$ & 9,8 \\
\hline $\begin{array}{l}\text { Зольность } \mathrm{A}^{\mathrm{d}} \\
\text { Ash content } \mathrm{A}^{\mathrm{d}}\end{array}$ & 1,2 \\
\hline $\begin{array}{l}\text { Выход летучих веществ } \mathrm{V}^{\text {daf }} \\
\text { Volatile content } \mathrm{V}^{\text {daf }}\end{array}$ & 80,2 \\
\hline
\end{tabular}

Элементный состав ${ }^{\mathrm{d}}$ мас. \%

Elementary composition ${ }^{\mathrm{d}}$, wt. \%

\begin{tabular}{|l|c|}
\multicolumn{2}{|c|}{ Elementary composition $^{2}$, wt. \% } \\
\hline $\mathrm{C}$ & 48,9 \\
\hline $\mathrm{H}$ & 5,9 \\
\hline $\mathrm{N}$ & 0,1 \\
\hline $\mathrm{S}$ & - \\
\hline $\mathrm{O}$ & 43,9 \\
\hline
\end{tabular}

\begin{tabular}{|l|c|}
\hline \multicolumn{2}{|c|}{ Материальный баланс, мaс. \% } \\
Material balance, wt. \% \\
\hline $\begin{array}{l}\text { Полукокс } \\
\text { Semi-coke }\end{array}$ & 30,0 \\
\hline $\begin{array}{l}\text { Парогазовая смесь } \\
\text { Gas-vapor mixture }\end{array}$ & 70,0 \\
\hline
\end{tabular}

Gas-vapor mixture

Состав парогазовых продуктов пиролиза, об. \% Composition of pyrolysis vapor, vol. \%

\begin{tabular}{|c|c|}
\hline $\mathrm{CO}$ & 32,3 \\
\hline $\mathrm{CO}_{2}$ & 30,4 \\
\hline $\mathrm{CH}_{4}$ & 20,3 \\
\hline $\mathrm{H}_{2}$ & 4,4 \\
\hline 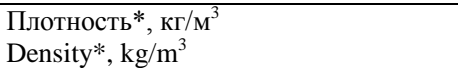 & 0,47 \\
\hline $\begin{array}{l}\text { Низшая теплота сгорания*, МДж/нм³ } \\
\text { Net calorific value*, } \mathrm{MJ} / \mathrm{nm}^{3}\end{array}$ & 9,01 \\
\hline
\end{tabular}

$r$ - рабочее состояние, ${ }^{d}$ - сухое состояние, ${ }^{d a f}$ - сухое беззольное состояние, *- плотность парогазовой смеси nрu meмnepamype $350^{\circ} \mathrm{C}$.

${ }^{r}$ - working condition, ${ }^{d}-d r y$ condition, daf - dry ash free,

* - density of the vapor-gas mixture at $350^{\circ} \mathrm{C}$.

Как видно из рис. 1 , извлечение образующихся парогазовых продуктов пиролиза осуществляется на стадии активного пиролиза посредством встроенного патрубка и тягодутьевого насоса. Определение коли- чественного состава газофазных продуктов $\left(\mathrm{CO}, \mathrm{CO}_{2}\right.$, $\left.\mathrm{CH}_{4}, \mathrm{H}_{2}\right)$ осуществлялось с помощью поточного газоанализатора Тест-1 (БОНЭР, Россия), пробоотборник которого был встроен в выхлопной патрубок пиролизной установки.

В таблице приведены результаты определения технических характеристик исходного сырья, материальный баланс получаемых продуктов и состав парогазовой смеси. Технические характеристики сырья (влажность, зольность, содержание летучих веществ) были определены с использованием стандартных методик ISO: ISO 589: 2008 «Каменный уголь - Определение общей влажности», ISO 1171: 2010 «Твердое минеральное топливо - Определение золы» и ISO 562: 2010 «Каменный уголь и кокс - Определение летучих веществ». Элементный состав был определен с помощью анализатора Flash 2000 CHNS (Thermo Fisher Scientific, США).

По данным таблицы количество образующихся парогазовых продуктов в процессе пиролиза древесных отходов (при расходе исходного вещества 0,5 т/ч) составляет $740,55 \mathrm{~m}^{3} /$ ч. Таким образом, количество располагаемого тепла $\mathrm{Q}_{\Gamma}^{\mathrm{P}}$, которое можно получить в результате сжигания парогазовой смеси, составляет около 1490 МДж/ч при температуре на выходе из установки $350{ }^{\circ} \mathrm{C}$.

\section{Циклы двигателей внутреннего сгорания и газотурбинных установок}

Для снижения операционных издержек на производство продукции в данной работе предлагается использовать возможность утилизации энергии, которая содержится в парогазовых продуктах пиролиза, выходящих из установки (рис. 1). Так как на нагрев ТЭНов для получения готовой продукции расходуется электрическая энергия, данный вид энергоносителя можно направить на работу установки, с помощью которой будет генерироваться электрическая энергия для компенсации собственных нужд.

В данной работе предложена следующая схема утилизации располагаемого тепла парогазовых продуктов пиролиза. Газы из пиролизной установки направляются в силовой агрегат, в котором в результате последовательных процессов сжатия, воспламенения, горения и расширения совершается работа на валу. Двигатель через муфту соединен с генератором, который вырабатывает электрическую энергию.

Для исследования эффективности работы силового агрегата в составе пиролизной установки при различных начальных температурах и составе газа были рассмотрены 4 термодинамических цикла: 2 цикла для ДВС (Тринклера, Отто) и 2 цикла для ГТУ (Гемфри, Брайтона). Данный выбор был обусловлен способностью силовых агрегатов данных типов к стабильной и надежной работе на исходном составе парогазовых продуктов пиролиза в широком диапазоне начальных температур (таблица).

На рис. 2, a в TS-координатах приведены процессы, протекающие в ДВС, работающих по циклам Тринклера, Отто, на рис. 2, б - процессы в ГТУ Брайтона, Гемфри. Процессы, протекающие в ДВС, 
построены в TS-координатах для температуры парогазовых продуктов пиролиза перед установкой $\mathrm{T}_{\mathrm{BX}}=350{ }^{\circ} \mathrm{C}$. При этом на рис. 2 , б циклы ГТУ постро- ены с процессом сжатия воздуха в воздушном компрессоре $\left(1-2^{\prime \prime \prime}\right)$, температура в точке $1^{\prime \prime}$ составляет $15{ }^{\circ} \mathrm{C}$.

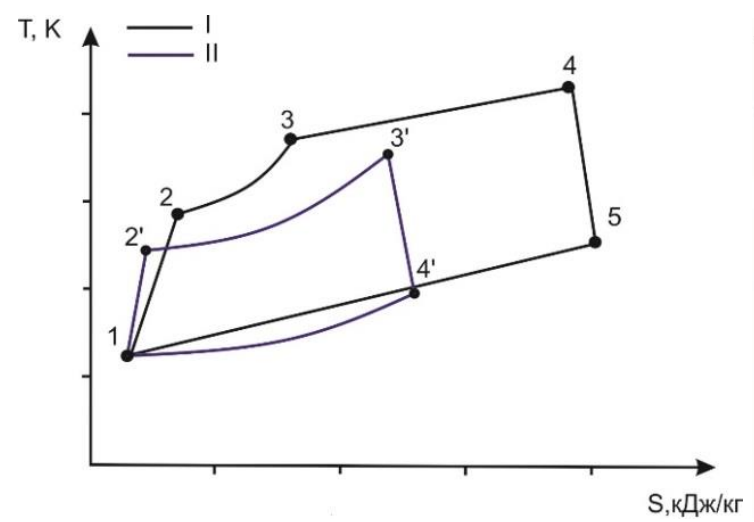

$a / a$

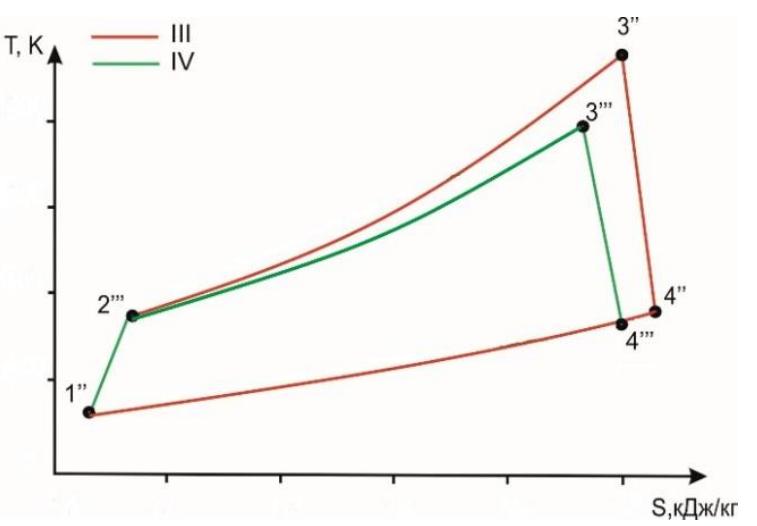

$6 / b$

Pис. 2. Термодинамические ичклы в TS-диаграмме: а) ииклы двигателей внутреннего сгорания, б) ииклы газотурбинных установок: I - Тринклера, II - Отто, III - Брайтона, IV - Гемфри

Fig. 2. Thermodynamic cycles in the TS-diagram: a) cycle of internal combustion engine, b) cycle of gas turbine unit: ITrinkler, II-Otto, III-Braithon, IV-Gemphri

Двигатель внутреннего сгорания Тринклера работает следующим образом. Воздух при температуре $15{ }^{\circ} \mathrm{C}$ подается через впускной клапан в цилиндр путем разрежения, создаваемого поршнем. Графически термодинамический цикл Тринклера изображен на рис. 2, $a$ (цикл I: 1-2-3-4-5). В адиабатном процессе 1-2 в цилиндре повышается давление и при помощи форсунок впрыскивается ППП. В результате высокого давления и температуры в точке 2 топливо самовоспламеняется в окислительной среде воздуха. В момент возгорания топлива поршень находится в верхней мертвой точке (BMT) 2. В процессе сжигания топлива 2-3 температура повышается, продукты сгорания расширяются и толкают поршень до пересечения с осью вала. Далее продукты сгорания топлива продолжают охлаждаться и расширяться в процессе 3-4, поршень движется до нижней мертвой точки (НMT). За счет того, что на коленчатом валу установлено несколько поршней, которые приводят его в движение, в определенный момент времени, поршень движется вверх по цилиндру в процессе 4-5, при этом открывается выпускной клапан, выхлопные газы удаляются в процессе $5-1$, и цикл начинается вновь.

Цикл Тринклера представляет собой модернизированный цикл Дизеля. За счет комбинированного способа подвода тепла для двигателей, работающих по данному термодинамическому циклу, они характеризуются высоким КПД и мощностью при относительно небольшом расходе топлива. В настоящее время цикл Тринклера для ДВС вытесняет традиционные циклы Дизеля за счет большей эффективности работы.

Двигатели внутреннего сгорания Отто отличаются интенсивным подводом топливно-воздушной смеси в свободный объем цилиндра через впускные клапаны в точке 1. Впуск осуществляется за счет разряжения, создаваемого прямым ходом поршня [18]. Графически термодинамический цикл Отто изображен на рис. 2, $a$ (цикл II: $\left.1-2^{\prime}-3^{\prime}-4^{\prime}\right)$. В адиабатном процессе 1-2 топливно-воздушная смесь сжимается, после чего поджигается свечей накаливания, и в процессе $2^{\prime}-3^{\prime}$ подводится теплота. Дальше в адиабатном процессе $3^{\prime}-4^{\prime}$ расширяется, совершая работу, и в изобарном процессе 4-1 отводится теплота. Основной особенностью данного термодинамического цикла относительно цикла Тринклера является воспламенение топливно-воздушной смеси, которое осуществляется от свечи накаливания, поэтому давление внутри цилиндра относительно небольшое, не требует установки дорогостоящих форсунок высокого давления.

В газотурбинной установке, работающей по циклу Брайтона $[19,20]$ (рис. $2, \sigma$, цикл III: $1^{\prime \prime}-2^{\prime \prime}-3^{\prime \prime}-4^{\prime \prime}$ ), в адиабатном процессе $1^{\prime \prime}-2$ " воздух сжимается в компрессоре и поступает с топливом в камеру сгорания, где в изобарном процессе $2^{\prime \prime}-3^{\prime \prime}$ подводится теплота от горящего топлива. Из камеры сгорания смесь продуктов сгорания и воздуха непрерывно поступают в турбину, где в адиабатном процессе 3 "I -4 расширяется и совершает работу, после чего в изобарном процессе $4^{\prime \prime}-1^{\prime \prime}$ отдает теплоту в окружающую среду. При меньшем термическом КПД цикл Брайтона получил более широкое применение относительно цикла Гемфри за счет более простой и надежной конструкции камеры сгорания и газовой турбины.

В газотурбинной установке, работающей по циклу Гемфри [19-22], процесс подвода теплоты при сгорании топлива, осуществляется при постоянном объеме в камере сгорания. Графически термодинамический цикл Гемфри изображен на рис. 2, 6 (цикл IV: $1^{\prime \prime}-2^{\prime \prime \prime}-$ $\left.3^{\prime \prime \prime}-4^{\prime \prime \prime}\right)$. В компрессоре, установленном на одном валу с газовой турбиной, в адиабатном процессе $1^{\prime \prime}-2^{\prime \prime \prime}$ сжимается воздух, который подается в камеру сгорания через впускной клапан. Одновременно с подводом воздуха в камеру сгорания подводится топливо с помощью топливного компрессора. При полностью закрытых впускных и выпускных клапанах происхо- 
дит горение топлива в изохорном процессе $2^{\prime \prime}-3^{\prime \prime \prime}$. В точке $3^{\prime \prime \prime}$ открывается выпускной клапан, через который смесь продуктов сгорания и воздуха поступает в газовую турбину, где в адиабатном процессе $3^{\prime \prime \prime}-4^{\prime \prime \prime}$ расширяется, приводя во вращение вал, после чего в изобарном процессе $4^{\prime \prime \prime}-1^{\prime \prime}$ отдает теплоту в окружающую среду.

Математические модели термодинамических циклов ДВС и ГТУ представляют собой системы уравнений, характеризующие процессы сжатия, горения и расширения в поршневых двигателях внутреннего сгорания и газотурбинных установках.

Теплофизические и термодинамические параметры топлива, продуктов сгорания и воздуха определяются с помощью функций библиотеки «Refprop 8.0» [23].

\section{Математические модели термодинамических циклов}

Математические модели составляются для определения параметров рабочих тел в характерных точках каждого термодинамического цикла.

Определение параметров для газов и их смесей осуществлялось с помощью привязанных функций Refprop 8.0. Температура, объем, давление, энтальпия энтропия и т. д. для воздуха, парогазовых продуктов пиролиза и продуктов их сгорания рассчитывались следующим образом:

Argument=function( $(« \mathrm{I} » ;\langle\langle\mathrm{II} » ;\langle\mathrm{III} » ;\langle\langle\mathrm{IV} » ;\langle\langle\mathrm{V} »)$,

где Argument - искомый параметр; function - функция, которая описывает параметр: pressure - давление, temperature - температура, volume - удельный объем, enthalpy - энтальпия, entropy - энтропия; заполняемые поля внутри функции: «I» - название рабочего тела, либо смеси жидкостей/газов, «II» - параметры, по которым определяется данная функция, например, температура и давление - «ТР», «III» - система измерения единиц - «SI», «IV» - значение первого параметра, « $\mathrm{V} »-$ значение второго параметра, по которому ищется функция.

Низшая теплота сгорания газа при нормальных условиях определяется по соотношению:

$$
\mathrm{Q}_{\mathrm{H}(\mathrm{H} \mathrm{Y})}^{\mathrm{P}}=\Sigma\left(\mathrm{Q}_{\mathrm{Hi}}^{\mathrm{P}} \mathrm{g}_{\mathrm{i}}\right), \mathrm{MД} / \mathrm{HM}^{3},
$$

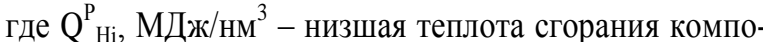
нента, определенная при н. у.; $\mathrm{g}_{i}, \%$ - относительное содержание компонента в газе, определяемое при н. у.

Низшая теплота сгорания газа при заданных условиях определяется по соотношению:

$$
\mathrm{Q}_{\mathrm{H}}^{\mathrm{P}}=\mathrm{Q}_{\mathrm{H}(\mathrm{Hy})}^{\mathrm{P}} \cdot \rho_{\mathrm{t}} / \rho_{\mathrm{Hy}}, \mathrm{MД} / \mathrm{Hм}^{3},
$$

где $\rho_{\mathrm{t}}, \kappa г / \mathrm{M}^{3}-$ плотность газа при заданной темпера-

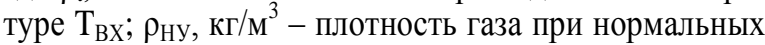
условиях.

\section{Цикл Тринклера}

Для расчета процессов цикла Тринклера были заданы следующие исходные параметры, состав газа и характеристики цикла:

- степень адиабатного сжатия воздуха в цилиндре $\varepsilon$;

- степень изохорного повышения давления в цилиндре $\lambda$ при самовоспламенении топлива под давлением;
- степень изобарного расширения в цилиндре ДВС за счет подвода тепла $\rho$;

- коэффициенты политропы $\mathrm{n}_{1}$ и $\mathrm{n}_{2}$.

Параметры рабочего тела в узловых точках определяются по следующим выражениям:

- параметры воздуха после сжатия:

$$
\begin{gathered}
\mathrm{p}_{2}=\mathrm{p}_{1} \cdot \varepsilon^{\mathrm{n} 1}, \mathrm{M \Pi a}, \\
\mathrm{T}_{2}=\mathrm{T}_{1} \cdot \varepsilon^{\mathrm{n} 1-1},{ }^{\circ} \mathrm{C}, \\
\mathrm{h}_{2}=\text { enthalpy («air»; «TP»; SI; } \mathrm{T}_{2} ; \mathrm{p}_{2} \text { ), } \\
\left.\mathrm{s}_{2}=\text { entropy («air»»; «TP»; SI; } \mathrm{T}_{2} ; \mathrm{p}_{2}\right) ;
\end{gathered}
$$

- параметры продуктов сгорания и воздуха в конце изохорного подвода тепла:

$$
\begin{gathered}
\mathrm{p}_{3}=\mathrm{p}_{2} \cdot \lambda, \mathrm{M \Pi а,} \\
\mathrm{T}_{3}=\mathrm{T}_{2} \cdot \lambda,{ }^{\circ} \mathrm{C},
\end{gathered}
$$

$$
\mathrm{h}_{3}=\text { enthalpy }\left(« \mathrm{cм} » ; \text { «TP»; SI; } \mathrm{T}_{3} ; \mathrm{p}_{3}\right) \text {, }
$$

где см - смесь продуктов сгорания и воздуха,

$$
\left.\mathrm{s}_{3}=\text { entropy («см»; «TP»; SI; } \mathrm{T}_{3} ; \mathrm{p}_{3}\right) ;
$$

- параметры продуктов сгорания при изобарном процессе подвода тепла:

$$
\begin{aligned}
& \mathrm{T}_{4}=\mathrm{T}_{3} \cdot \rho,{ }^{\circ} \mathrm{C}, \\
& v_{4}=v_{3} \cdot \rho, \mathrm{m}^{3} / \kappa \Gamma, \\
& \mathrm{p}_{4}=\mathrm{p}_{3}, \text { МПа, } \\
& \mathrm{h}_{4}=\text { enthalpy }\left(« \mathrm{~cm} » ;\left\langle\mathrm{TP} » ; \mathrm{SI} ; \mathrm{T}_{4} ; \mathrm{p}_{4}\right)\right. \text {, } \\
& \mathrm{s}_{4}=\text { entropy }\left(« \mathrm{~cm} » ; \text { «TP»; SI; } \mathrm{T}_{4} ; \mathrm{p}_{4}\right)
\end{aligned}
$$

- параметры сгорания при изохорном отводе тепла:

$$
\begin{gathered}
\mathrm{p}_{5}=\mathrm{p}_{4} \cdot\left(\mathrm{v}_{4} / \mathrm{v}_{5}\right)^{\mathrm{n} 2}, \mathrm{M \Pi а}, \\
\mathrm{v}_{5}=\mathrm{v}_{4}, \mathrm{M}^{3} / \mathrm{\kappa} \Gamma, \\
\mathrm{T}_{5}=\text { temperature }\left(« \mathrm{~cm} » ;\left\langle\mathrm{PV} » ; \mathrm{SI} ; \mathrm{p}_{5} ; \mathrm{v}_{5}\right),\right. \\
\mathrm{h}_{5}=\text { enthalpy }\left(« \mathrm{~cm} » ; \ll \mathrm{TP} » ; \mathrm{SI} ; \mathrm{T}_{5} ; \mathrm{p}_{5}\right), \\
\mathrm{s}_{5}=\text { entropy }\left(« \mathrm{cм} » ; \ll \mathrm{TP} » ; \mathrm{SI} ; \mathrm{T}_{5} ; \mathrm{p}_{5}\right) .
\end{gathered}
$$

\section{Цикл Отто}

Цикл с подводом тепла при постоянном объеме частный случай модели двигателя Тринклера. Для цикла Отто отсутствует подвод тепла при постоянном давлении. Задаваемые параметры аналогичны таковым для цикла Тринклера, степень изобарного расширения $\rho=1$.

\section{Цикл Брайтона}

- степень предварительного расширения при сгорании топлива:

$$
\rho=v_{3^{\prime \prime}} / v_{4^{\prime \prime}}
$$

Параметры воздуха и продуктов сгорания топлива в узловых точках определяются по следующим соотношениям:

- после воздушного компрессора:

$$
\begin{gathered}
\mathrm{v}_{2^{\prime \prime}}=\mathrm{v}_{1^{\prime \prime}} / \pi^{(1 / \mathrm{n} 1)}, \mathrm{M}^{3} / \mathrm{\kappa}, \\
\mathrm{p}_{2}{ }^{\prime \prime}=\mathrm{p}_{1}{ }^{\prime \prime} \cdot \pi, \mathrm{MПа},
\end{gathered}
$$


$\mathrm{T}_{2}$ =temperature $« \mathrm{~cm} » ;\left(« \mathrm{PV} » ; \mathrm{SI} ; \mathrm{p}_{2} " ; \mathrm{v}_{2} "\right),{ }^{\circ} \mathrm{C}$,

$\mathrm{h}_{2}$ " и $\mathrm{s}_{2}$ определяются аналогично соотношениям (6), (7);

- в камере сгорания:

$$
\begin{gathered}
v_{3}=v_{2}, \cdot \rho, \mathrm{m}^{3} / \mathrm{\kappa} ; \\
\mathrm{p}_{3}{ }^{\prime \prime}=\mathrm{p}_{2}, \mathrm{M \Pi а} ;
\end{gathered}
$$

$\mathrm{h}_{3 \text { " и }} \mathrm{S}_{3}$ определяются аналогично соотношениям (10), (11);

- после газовой турбины:

$$
\begin{gathered}
\mathrm{p}_{4}{ }^{\prime \prime}=\mathrm{p}_{1 "}, \mathrm{M \Pi а}, \\
v_{4}=v_{1}{ }^{\prime \prime}\left(\mathrm{p}_{3}{ }^{\prime \prime} / \mathrm{p}_{4}\right)^{1 / \mathrm{n} 2}, \mathrm{M}^{3} / \kappa \Gamma,
\end{gathered}
$$

$\mathrm{T}_{4}=$ temperature $\left(« \mathrm{CM} » ;\left\langle\mathrm{PV} » ; \mathrm{SI} ; \mathrm{p}_{4} " ; \mathrm{v}_{4}\right),{ }^{\circ} \mathrm{C}\right.$.

\section{Цикл Гемфри}

Задаются исходные параметры, состав газа и следующие характеристики цикла:

- степень адиабатного повышения давления воздуха в компрессоре:

$$
\pi=\mathrm{p}_{2}, \cdot \mathrm{p}_{1}{ }^{\prime \prime} ;
$$

- степень изохорного повышения давления продуктов сгорания за счет подвода тепла в камере сгорания:

$$
\lambda=\mathrm{p}_{3, \cdots} / \mathrm{p}_{2}{ }^{\prime \prime} .
$$

Параметры воздуха и продуктов сгорания топлива в узловых точках определяются по следующим соотношениям:

- после воздушного компрессора аналогично циклу Брайтона (23)-(25);

- в камере сгорания:

$$
\begin{gathered}
v_{3}{ }^{\prime \prime}=v_{2}{ }^{\prime \prime} \cdot \rho, \mathrm{m}^{3} / \kappa г, \\
\mathrm{p}_{3^{\prime \prime}}=\mathrm{p}_{2}{ }^{\prime \prime} \cdot \lambda, \mathrm{M \Pi а},
\end{gathered}
$$

$\mathrm{T}_{3 "}=$ =temperature («cм»; «PV»; SI; $\left.\mathrm{p}_{3}{ }^{\prime \prime} ; \mathrm{v}_{3}{ }^{\prime \prime}\right),{ }^{\circ} \mathrm{C}$,

$\mathrm{h}_{3}$ ”' и $\mathrm{s}_{3}$ ”' определяются аналогично соотношениям (10), (11);

- после газовой турбины:

$$
\begin{aligned}
& v_{4^{\prime \prime}}=v_{3^{\prime \prime \prime}} \cdot\left(\mathrm{p}_{3^{\prime \prime}} / \mathrm{p}_{4^{\prime \prime \prime}}\right)^{1 / \mathrm{n} 2}, \\
& \mathrm{p}_{4} \text { "'= } \mathrm{p}_{3 " ',} \text { МПа, }
\end{aligned}
$$

$\mathrm{T}_{4}{ }^{\prime \prime}=$ temperature («см»; «TP»; SI; $\left.\mathrm{p}_{4}{ }^{\prime \prime} ; \mathrm{v}_{4}{ }^{\prime \prime}\right),{ }^{\circ} \mathrm{C}$,

$\mathrm{h}_{4}$ "' и $\mathrm{s}_{4}$ "' определяются аналогично соотношениям (15), (16).

\section{Расчет показателей силового агрегата}

Внутренний КПД для цикла Тринклера определяется по уравнению:

$$
\eta_{\mathrm{i}}=\left[\left(\mathrm{h}_{4}-\mathrm{h}_{5}\right)-\left(\mathrm{h}_{2 \mathrm{CM}}-\mathrm{h}_{1}\right)-\alpha_{\Gamma}\left(\mathrm{h}_{2 \mathrm{TK}}-\mathrm{h}_{1^{\prime}}\right)\right] \cdot 100 /\left(\mathrm{h}_{4}-\mathrm{h}_{2 \mathrm{CM}}\right), \%,
$$

где $\mathrm{h}_{2 \mathrm{~cm}}$ - энтальпия смешения газов и воздуха в камере сгорания, определяется по тепловому балансу, кДж/кг; $\mathrm{h}_{2 к}$ - энтальпия газов после топливного компрессора, кДж/кг; $\alpha_{\Gamma}-$ коэффициент содержания газов в топливно-воздушной смеси.

Внутренний КПД для цикла Отто определяется по соотношению:

$$
\eta_{\mathrm{i}}=\left[\left(\mathrm{h}_{3}-\mathrm{h}_{4}\right)-\left(\mathrm{h}_{2 \mathrm{CM}}-\mathrm{h}_{1}\right)-\alpha_{\Gamma}\left(\mathrm{h}_{2 \mathrm{TK}}-\mathrm{h}_{1^{\prime}}\right)\right] \cdot 100 /\left(\mathrm{h}_{3}-\mathrm{h}_{2}\right), \%,
$$

Внутренний КПД для циклов Брайтона, Гемфри определяется по уравнению:

$$
\eta_{\mathrm{i}}=\left[\left(\mathrm{h}_{3}-\mathrm{h}_{4}\right)-\left(\mathrm{h}_{2 \mathrm{CM}}-\mathrm{h}_{1}\right)\right] \cdot 100 /\left(\mathrm{h}_{3}-\mathrm{h}_{2}\right), \%,
$$

Абсолютный электрический КПД термодинамических циклов:

$$
\eta_{\ni}=\eta_{\mathrm{i}} \cdot \eta_{\ni \mathrm{M}}, \%,
$$

где $\eta_{э м}=0,96$ - КПД, учитывающий электромеханические потери.

Электрическая мощность рассчитывается из теплового баланса установки:

$$
\mathrm{N}_{\ni}=Q_{\Gamma}^{\mathrm{P}} \cdot \eta_{\ni}, \% \text {. }
$$

На основе уравнений (1)-(43) для описанных моделей термодинамических циклов ДВС и ГТУ составлена программа, написанная в MS Office Excel с подключенными функциями свойств веществ «Refprop $8.0 \gg[23]$.

Так как действительные процессы в ДВС и ГТУ имеют сложный характер, а рабочие тела (воздух, горючие газы, продукты сгорания и т. д.) представляют собой комплексные смеси различных веществ, были сделаны следующие допущения:

- рассматриваются замкнутые циклы;

- силовой агрегат работает в стационарном режиме;

- воздух имеет количественный состав: $\mathrm{N}_{2} 79 \%, \mathrm{O}_{2}$ $21 \%$, температура на входе в агрегат $+15{ }^{\circ} \mathrm{C}$;

- давление окружающей среды постоянное и имеет значение $\mathrm{p}_{1}=0,095 \mathrm{MПа;}$

- состав продуктов сгорания топлива определяется теоретическими объемами компонентов при сжигании $1 \mathrm{~m}^{3}$ топлива.

- не учитываются тепловые и механические потери в оборудовании.

- приняты рекомендуемые параметры работы оборудования: коэффициенты политропы для циклов ГТУ $\mathrm{n}_{1}=1,41$ и $\mathrm{n}_{2}=1,24$, для ДВС: $\mathrm{n}_{1}=1,36$ и $\mathrm{n}_{2}=1,24$; $\varepsilon=12 ; \lambda=1,3 ; \rho=1,2 ; \pi=12$ [18-20].

Bce представленные выше допущения позволяют проводить исследование термодинамических циклов силовых агрегатов в широком диапазоне параметров и состава газов.

С помощью программы были произведены расчеты при изменении температуры парогазовых продуктов пиролиза на входе в двигатель $\mathrm{T}_{\mathrm{BX}}$ в рекомендуемом диапазоне работы пиролизной установки $350-450{ }^{\circ} \mathrm{C}$ и при различных составах сжигаемого топлива. Полученные в результате расчета зависимости электрического КПД брутто и мощности двигателя от $\mathrm{T}_{\mathrm{BX}}$ приведены на рис. 3. График зависимости температуры уходящих газов от температуры $\mathrm{T}_{\mathrm{BX}}$ приведен на рис. 4. Следующее исследование заключалось в анализе мощностных характеристик силовых агрегатов от состава сжигаемого газа при смешивании парогазовых продуктов с $\mathrm{CH}_{4}$ в пропорциях 0,25 , 50,75 и $100 \%$ от общего объема топлива при темпеpaтуре $\mathrm{T}_{\mathrm{BX}}=350{ }^{\circ} \mathrm{C}$. Графическая зависимость электрической мощности, выдаваемой генератором от состава сжигаемого газа, приведена на рис. 5. 


\section{Результаты и обсуждение}

Плотность исследуемых парогазовых продуктов при неизменном составе (таблица) зависит от давления и температуры: при атмосферном давлении и температуре $25^{\circ} \mathrm{C}$ плотность исследуемых газов составляет $0,99 \mathrm{\kappa} / \mathrm{M}^{3}$, при $350{ }^{\circ} \mathrm{C}$ плотность газа с за-

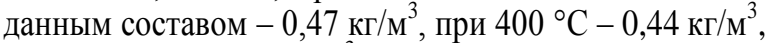
при $500{ }^{\circ} \mathrm{C}-0,39 \mathrm{\kappa} / \mathrm{m}^{3}$. Плотность в значительной степени определяет объем $\left(\mathrm{V}_{\text {Пп }}\right)$ выхода парогазовых продуктов при неизменной загрузке исходного сырья (500 кг/ч) в пиролизную установку (рис. 1): при $350{ }^{\circ} \mathrm{C} \mathrm{V}_{\text {пп }}$ составляет $741 \mathrm{~m}^{3} / \mathrm{u}$, при $400{ }^{\circ} \mathrm{C}-800 \mathrm{~m}^{3} / \mathrm{ч}$, при $500{ }^{\circ} \mathrm{C}-908 \mathrm{~m}^{3} /$ ч. Данный фактор определяет располагаемое тепло, вносимое с парогазовыми продуктами пиролиза в силовой агрегат - при увеличении температуры снижается $\mathrm{Q}_{\Gamma}^{\mathrm{P}}$.

В термодинамическом цикле Тринклера воздух сжимается поршнем в процессе 1-2 до $\mathrm{p}_{2}=2,18$ МПа и $\mathrm{t}_{2}=1154{ }^{\circ} \mathrm{C}$; топливо подается под давлением $\mathrm{p}_{2}$ в цилиндр и в процессе 2-3 и 3-4 в ходе изохорного и изобарного процессов подвода тепла температура газовоздушной смеси повышается до $\mathrm{t}_{4}=1879^{\circ} \mathrm{C}$; в процессе расширения газов в цилиндре 4-5 температура снижается до $\mathrm{t}_{4}=984{ }^{\circ} \mathrm{C}$; в 5-1 уходящие газы удаляются из цилиндра.

В цикле Отто газо-воздушная смесь сжимается в процессе $1-2^{\prime}$ до давления $\mathrm{p}_{2}=2,83$ МПа и $\mathrm{t}_{2}=1154{ }^{\circ} \mathrm{C}$, затем она воспламеняется свечой зажигания и в процессе изохорного подвода тепла $2^{\prime}-3^{\prime}$ температура повышается до $1779{ }^{\circ} \mathrm{C}$, далее газы толкают поршень и расширяются в процессе $3{ }^{\prime}-4^{\prime}$ при этом температура отвода выхлопных газов составляет $\mathrm{t}_{4},=931^{\circ} \mathrm{C}$.

В цикле Брайтона воздух сжимается компрессором в процессе $1^{\prime \prime}-2^{\prime \prime}$ до $\mathrm{p}_{2 "}=1,14$ МПа и $\mathrm{t}_{2}=317^{\circ} \mathrm{C}$, в процессе $2^{\prime \prime}-3^{\prime \prime}$ подводится тепло в постоянном объеме камеры сгорания, и температура газов повышается до $\mathrm{t}_{3,}=1094^{\circ} \mathrm{C}$, в турбине газы расширяются в процессе $3^{\prime \prime}-4^{\prime \prime}$ и удаляются с $\mathrm{t}_{4}=574^{\circ} \mathrm{C}$.

В цикле Гемфри воздух сжимается воздушным компрессором в процессе $1^{\prime \prime}-2^{\prime \prime \prime}$ до $\mathrm{p}_{2}$ "'=1,14 МПа и $\mathrm{t}_{2,},=317{ }^{\circ} \mathrm{C}$, в процессе $2^{\prime \prime \prime}-3^{\prime \prime \prime}$ в камере сгорания за счет сжигания топлива в окислительной среде сжатого воздуха подводится тепло при постоянном давле-

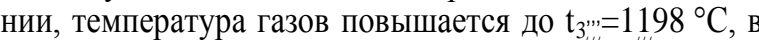
турбине газы расширяются в процессе $3^{\prime \prime \prime}-4^{\prime \prime \prime}$, производя работу на валу, и удаляются в атмосферу при $\mathrm{t}_{4}, "=594{ }^{\circ} \mathrm{C}$.

На рис. 3 приведена зависимость КПД и мощности от $\mathrm{T}_{\mathrm{BX}}$ для всех рассматриваемых термодинамических циклов. Она имеет линейный характер. Показатели эффективности работы установок - электрической мощности и абсолютного электрического КПД для циклов Тринклера и Отто - незначительно снижаются при повышении $\mathrm{T}_{\mathrm{BX}}$, а для циклов Брайтона и Гемфри повышаются. Увеличение КПД для термодинамических циклов Брайтона, Отто при повышении $\mathrm{T}_{\mathrm{BX}}$ обусловлено ростом соотношения производимой работы к подводимому теплу.

Мощностная характеристика для двигателя, работающего по термодинамическому циклу Тринклера, при повышении $\mathrm{T}_{\mathrm{BX}}$ на $5^{\circ} \mathrm{C}$ в силовой агрегат снижа- ется на 0,57\%. Воспламенение топливно-воздушной смеси происходит за счет сжатия в цилиндре, при более высокой температуре подвода тепла требуется создание большего давления. Наибольшим приростом мощности и КПД при увеличении начальной температуры газов обладает газотурбинная установка, работающая по термодинамическому циклу Брайтона. В данном случае увеличение $\mathrm{T}_{\mathrm{BX}}$ приводит к снижению относительной доли подвода тепла в камере сгорания, за счет чего растет эффективность ГТУ и температура на входе в турбину. Увеличение температуры газов при их неизменном составе на входе газовую турбину способствует повышению ее мощности.

В базовом режиме работы пиролизной установки, выдающей температуру парогазовых продуктов на выходе $\mathrm{T}_{\mathrm{BX}}=350{ }^{\circ} \mathrm{C}$, наибольшей эффективностью обладает двигатель, работающий по термодинамическому циклу Тринклера с абсолютным электрическим КПД 23,34 \% и мощностью 96,6 кВт. Высокие показатели при относительно низкой $\mathrm{T}_{\mathrm{BX}}$ цикла Тринклера обусловлены комбинированным способом подвода тепла. При температуре $\mathrm{T}_{\mathrm{BX}}=350{ }^{\circ} \mathrm{C}$ термодинамический цикл Брайтона имеет $\eta_{\ni}=14,19 \%$, Отто $20,63 \%$, Гемфри - 22,28 \%. При увеличении температуры до $\mathrm{T}_{\mathrm{BX}}=450{ }^{\circ} \mathrm{C}$ абсолютный электрический КПД растет, а электрическая мощность ДВС и ГТУ снижается, что видно на рис. 3, при этом для цикла Гемфри отмечен рост мощности. Снижение электрической мощности связано с уменьшением располагаемого тепла, вносимого с парогазовыми продуктами пиролиза при более высокой температуре. Увеличение термического и электрического КПД связано с увеличением температуры подвода тепла в циклах. При температуре $450{ }^{\circ} \mathrm{C}$ наибольшим КПД обладает ГТУ цикла Гемфри - 26,41 \% и ДВС цикла Тринклера $23,97 \%$

Для ГТУ при заданных параметрах работы в рассмотренном температурном диапазоне цикл Гемфри имеет мощность и КПД выше, чем цикл Брайтона. Это связано с большой мощностью газовой турбиной при неизменных параметрах работы установок (рис. 2).

При анализе данных, полученных при изменении начальной температуры ППП, представленных на рис. $3, a, \sigma$, видно, что для термодинамических циклов Тринклера и Отто электрический КПД возрастает, при этом мощность падает при увеличении $\mathrm{T}_{\mathrm{BX}}$. Как упоминалось ранее, при росте температуры низшая теплота сгорания ППП, отнесенная к объему, уменьшается, поэтому вносимое тепло снижается. В свою очередь абсолютный электрический КПД цикла зависит от термического КПД. Для термодинамических циклов двигателей внутреннего сгорания начальная температура топлива не оказывает значительного влияния на среднюю температуру подвода тепла. Температура подвода тепла в ДВС зависит в большей степени от степени сжатия и давления подаваемого воздуха и топлива.

При рассмотрении данных мощности и КПД для термодинамических циклов Брайтона и Гемфри отмечена прямая зависимость - при росте начальной тем- 
пературы газов показатели увеличиваются. В ГТУ газ, подаваемый в камеру сгорания, окисляется и горит в постоянном объеме камеры сгорания, имеются отличия в способе подачи топлива и отвода продуктов сгорания. Поэтому повышение температуры подвода топлива приводит к увеличению температуры про- дуктов сгорания на входе в газовую турбину, следовательно, возрастает теплоперепад и мощность, генерируемая установкой. При увеличении температуры газов в термодинамическом цикле повышается средняя температура подвода тепла, следовательно, растет термический и абсолютный электрический КПД.
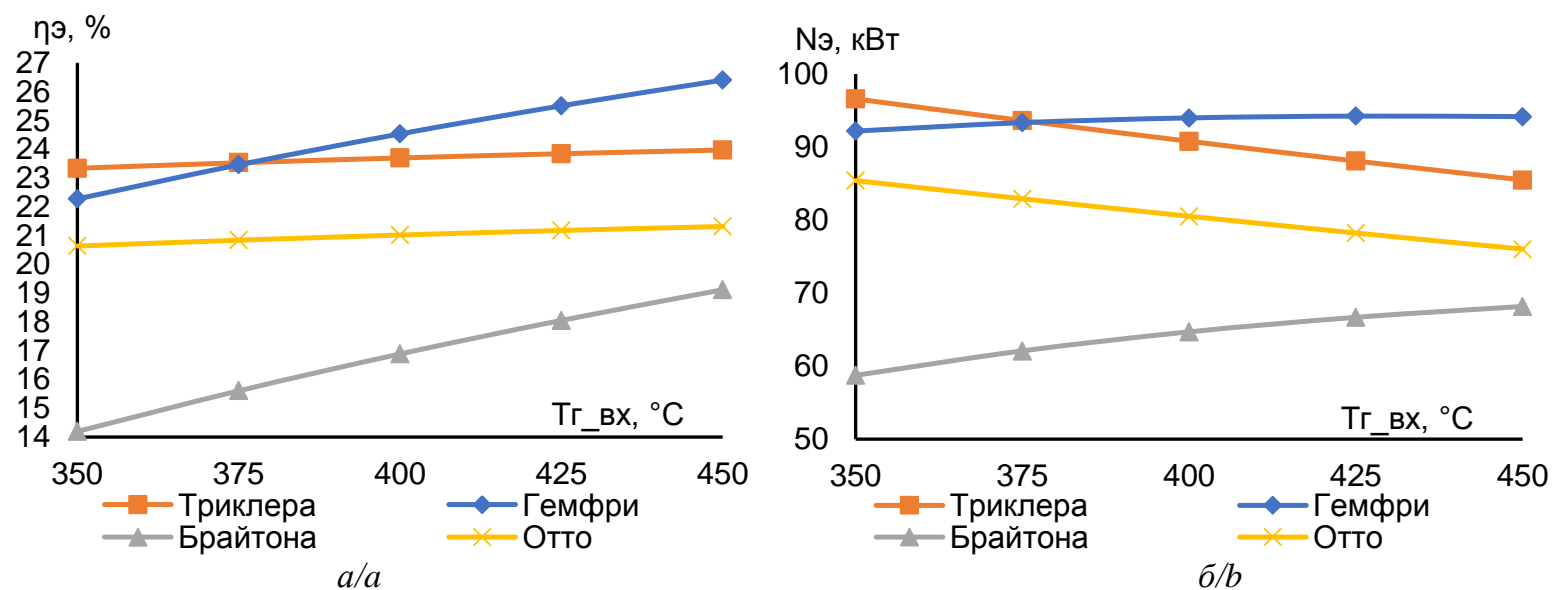

Рис. 3. Зависимость изменения электрического КПД (а) и мощности (б) двигателя от начальной температуры парогазовых продуктов пиролиза

Fig. 3. Dependence of the change of electrical efficiency $(a)$ and power $(b)$ of the power-unit on the initial stem product pyrolysis $(S P P)$ temperature

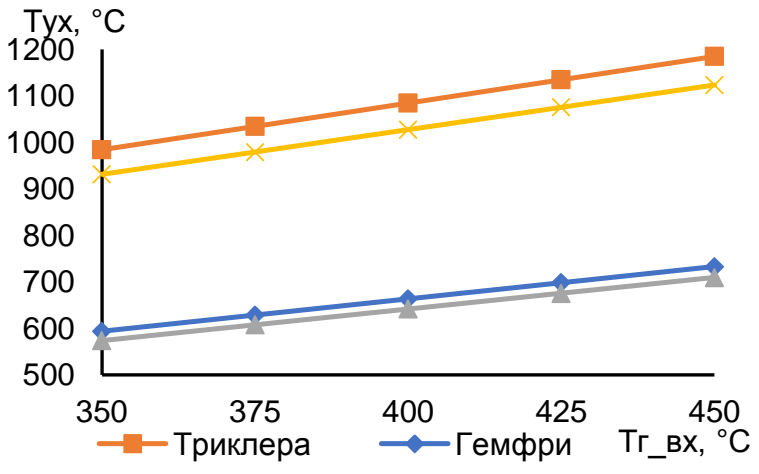

Рис. 4. Зависимость изменения температуры уходящих газов силового агрегата от температуры парогазовых продуктов на входе в двигатель

Fig. 4. Dependence of the change in the temperature of the outgoing gases of the power-unit on the initial SPP temperature

На рис. 4 приведены зависимости изменения температуры уходящих газов $\mathrm{T}_{\mathrm{yx}}$ от $\mathrm{T}_{\mathrm{Bx}}$ для всех рассматриваемых термодинамических циклов, которые имеют линейный характер. Температуры $\mathrm{T}_{\mathrm{yx}}$ для циклов Тринклера и Отто имеют значения выше $900{ }^{\circ} \mathrm{C}$ при $\mathrm{T}_{\mathrm{BX}}=350{ }^{\circ} \mathrm{C}$ и при росте $\mathrm{T}_{\mathrm{BX}}$ линейно возрастают. Температуры $\mathrm{T}_{\mathrm{yx}}$ для циклов Гемфри и Брайтона имеют значения ниже $600{ }^{\circ} \mathrm{C}$ при $\mathrm{T}_{\mathrm{BX}}=350{ }^{\circ} \mathrm{C}$ и при росте $\mathrm{T}_{\mathrm{BX}}$ линейно возрастают. При этом наклон всех линейных зависимостей $\mathrm{T}_{\mathrm{yx}}$ от $\mathrm{T}_{\mathrm{BX}}$ имеет равное значение, кривые не пересекаются.

Температура уходящих газов на выходе из силового агрегата для каждого выбранного термодинамического цикла с заданными параметрами имеет свой диапазон. Полученные кривые (рис. 4) имеют линей- ный характер для всех исследуемых циклов: $\mathrm{T}_{\mathrm{yx}}$ повышается при увеличении $\mathrm{T}_{\mathrm{BX}}$. Рост $\mathrm{T}_{\mathrm{yx}}$ объясняется переходом режима работы агрегата в область более высоких температур подвода тепла при неизменных параметрах $\varepsilon, \lambda, \rho, \pi$.

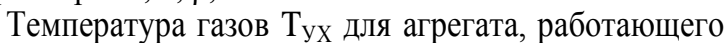
по термодинамическому циклу Брайтона, во всем исследуемом диапазоне температур имеет наименьшие значения: в базовом режиме при $\mathrm{T}_{\mathrm{BX}}=350-450{ }^{\circ} \mathrm{C}$ $\mathrm{T}_{\mathrm{yx}}=574-710^{\circ} \mathrm{C}$. Низкая температура $\mathrm{T}_{\mathrm{yx}}$ на рис. 4 объясняется высокой тепловой отдачей в газовой турбине, которая вырабатывает наибольшую мощность в заданных условиях (рис. 3,6 ).

Для агрегата, работающего по термодинамическому циклу Тринклера, при $\mathrm{T}_{\mathrm{BX}}=350{ }^{\circ} \mathrm{C} \mathrm{T}_{\mathrm{yx}}=984{ }^{\circ} \mathrm{C}$ и далее увеличивается с ростом температуры ППП на входе в камеру сгорания.

На рис. 5 приведены данные зависимости электрической мощности выдаваемого генератором силового агрегата от состава сжигаемого газа. В качестве основных компонентов газа были выбраны метан $\left(\mathrm{CH}_{4}\right)$ и парогазовые продукты пиролиза (таблица). Эти два компонента предполагается смешивать объемных долях 0/100, 25/75, 50/50, 75/25, 100/0. При этом в качестве вторичного компонента используется ППП. Цель данного исследования - изучить возможность использования газовых смесей на основе $\mathrm{CH}_{4}$ и ППП в качестве топлива для силового агрегата, генерирующего электрическую энергию.

При увеличении в топливной смеси содержания природного газа $\left(\mathrm{CH}_{4}\right)$ при температуре $350^{\circ} \mathrm{C}$ мощность электрогенератора значительно возрастает. Вопервых, низшая теплота сгорания метана составляет $\mathrm{Q}_{\mathrm{H}}^{\mathrm{P}}=35,88$ МДж/ $\mathrm{Hм}^{3}$, в то время как для ППП 
$\mathrm{Q}^{\mathrm{P}}{ }_{\mathrm{H}}=9,01 \mathrm{MДж/ \textrm {m } ^ { 3 }}$ (таблица). Во-вторых, метан имеет меньшую плотность, поэтому его объемный выход значительно больше, чем ППП. В камере сгорания сжигается большее количество топлива с более высокой теплотворной способностью. На рис. 5 видно, что при полном замещении ППП метаном мощность агрегатов возрастает приблизительно в 4 раза. В реальных условиях оборудование не может иметь такой рабочий диапазон.

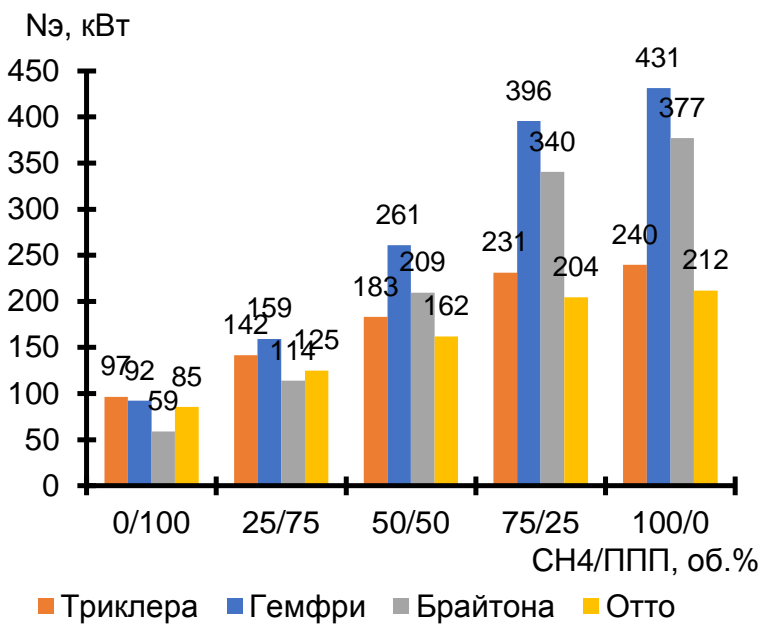

Рис. 5. Зависимость изменения электрической мощности от состава газов ( $\mathrm{CH}_{4} /$ парогазовые продукты пиролиза, об. \%) на входе в силовой агрегат

Fig. 5. Dependence of electrical power change of the powerunit on the composition of gases $\left(\mathrm{CH}_{4} / \mathrm{SPP}\right.$, vol. \%)

На совмещенной установке пиролиза древесных отходов и электрогенератора, использующего в качестве основного топлива ППП для удовлетворения роста в потребностях электрической энергии, можно к исходному составу парогазовых продуктов пиролиза подмешивать природный газ - метан. При увеличении объемного содержания метана в ППП на $25 \%$ электрическая мощность ДВС возрастает на 46-47 \%, ГТУ - на 73-93 \% (рис. 5). При эксплуатации силового агрегата, генерирующего электроэнергию и использующего в качестве основного топлива сжатый природный газ, подмешивание парогазовых продуктов пиролиза с объемным содержанием $25 \%$ приводит к снижению мощности на 8-10\%, что является допустимым условием эксплуатации.

\section{Предложения по направлению} дальнейших исследований

Для более подробного рассмотрения каждого силового агрегата требуется поиск и оптимизация рабочих параметров и процессов оборудования, определение конструктивных особенностей при работе на парогазовых продуктах пиролиза при высокой температуре подвода топливно-воздушной смеси. Высокую температуру уходящих газов из силового агрегата можно снижать путем преобразования энергии в нижнем цикле Ренкина. Уходящие газы направляются в теплообменник противоточного типа, в котором тепловая энергия передается через поверхности нагрева нижнему контуру. Рабочее тело нагревается в теплообменнике, преобразуется в пар и направляется в паровую турбину, где расширяется в проточной части, передавая энергию расширения в энергию на валу. Таким образом, можно снизить температуру продуктов сгорания до температуры $100-120^{\circ} \mathrm{C}$, а суммарный КПД по выработке электроэнергии может достичь 45-50\% [24, 25].

Проведенные расчеты показывают, что высокие КПД, мощность и температура уходящих газов термодинамического цикла Тринклера относительно всех рассмотренных циклов делают его привлекательным для исследований совместной работы с нижним контуром, который работает на органическом цикле Ренкина.

\section{Выводы}

1. Разработана и предложена схема получения парогазовых продуктов пиролиза и их последующее использование в качестве основного или вспомогательного энергоносителя для генерации электрической энергии. Рассмотрены двигатели внутреннего сгорания и газотурбинные установки, работающие на четырех термодинамических циклах: Тринклера, Отто, Брайтона и Гемфри. Составлена математическая модель для определения показателей эффективности генерации электрической энергии при сжигании парогазовых продуктов пиролиза.

2. Для рассмотренных термодинамических циклов проведен численный анализ влияния температуры парогазовых продуктов пиролиза на входе в силовой агрегат на электрическую мощность, КПД и температуру уходящих газов из силового агрегата. Определено, что рост $\mathrm{T}_{\mathrm{BX}}$ снижает мощность и КПД для силовых агрегатов, работающих по циклам Тринклера и Гемфри, и приводит к повышению показателей эффективности для циклов Отто и Брайтона. Для базовой температуры, при которой в пиролизной установке образуются парогазовые продукты $\left(350{ }^{\circ} \mathrm{C}\right)$, наибольшей электрической мощностью $\mathrm{N}_{\ni}=96,6$ кВт и КПД $\eta_{\ni}=23,34$ \% обладает двигатель Тринклера и газотурбинная установка Брайтона: $\mathrm{N}_{\ni}=92,2$ кВт и КПД $\eta_{\ni}=22,28 \%$.

3. Для всех рассмотренных агрегатов рост $\mathrm{T}_{\mathrm{BX}}$ приводит к линейному увеличению $\mathrm{T}_{\text {ух }}$. Наибольши-

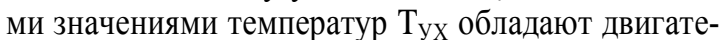
ли внутреннего сгорания (Тринклера и Отто). Высокие температуры $\mathrm{T}_{\mathrm{yx}}$ совместно с высоким электрическим КПД рассмотренных установок позволяют их рассматривать в качестве верхнего цикла для утилизации тепла уходящих газов в цикле Ренкина на ОРТ.

4. Выявлено, что использование метана в качестве примеси для парогазовых продуктов пиролиза позволяет увеличить вырабатываемую электроэнергию: для силового агрегата, работающего на термодинамическом цикле Тринклера, объемное содержание $\mathrm{CH}_{4} 25 \%$ и ППП $75 \%$ в сжигаемом газе приводит к увеличению электрической мощности на $46 \%$ относительно электродвигателя, сжигающего газ, состоящий из 100 \% ППП. 
Работа выполнена при финансовой поддержке в соответствии с дополнительным соглашением № 075-032021-138/3 о предоставлении субсидии из федерального

\section{СПИСОК ЛИТЕРАТУРЫ}

1. King R., Tingas E.-A. Potential for carbon-neutral advanced biofuels in UK road transport // Journal of Energy Engineering. 2021. - V. 147 (4). - P. 04021025.

2. Jha G., Soren S., Deo Mehta K. Partial substitution of coke breeze with biomass and charcoal in metallurgical sintering // Fuel. 2020. - V. 278. - P. 118350

3. Progress on the lignocellulosic biomass pyrolysis for biofue production toward environmental sustainability / A.T. Hoang, H.C. Ong, I.M.R. Fattah, R. Sakthivel // Fuel Processing Technology. 2021. - V. 223. - P. 106997.

4. Balat M., Kirtay E., Balat H. Main routes for the thermoconversion of biomass into fuels and chemicals. P. 1: Pyrolysis systems // Energy Conversion and Management. - 2009. № 50 (12). - P. 3147-3157.

5. Biofuels production through biomass pyrolysis - a technologica review / M.I. Jahirul, M.G. Rasul, A.A. Chowdhury, N. Ashwath // Energies. - 2012. - № 5 (12). - P. 4952-5001.

6. Получение брикетированного полукокса из древесных отходов методом стадийного низкотемпературного пиролиза К.Б. Ларионов, С.А. Янковский, В.Е. Губин, А.А. Улько // Кокс и химия. -2020 . - № 12. - С. 40-48.

7. Norms and standards for pyrolysis liquids. End-user requirements and specifications / A. Oasmaa, C. Peacocke, S. Gust, D. Meier R. McLellan // Energy and Fuels. - 2005. - № 19 (5). - P. 2155-2163.

8. Kan T., Strezov V., Evans T.J. Lignocellulosic biomass pyrolysis: a review of product properties and effects of pyrolysis parameters // Renewable and Sustainable Energy Reviews. - 2016. - № 57. P. 1126-1140.

9. Valorization of pyrolysis water: a biorefinery side stream, for 1,2propanediol production with engineered Corynebacterium glutamicum / J. Lange, F. Müller, K. Bernecker, R. Takors // Biotechnology for Biofuels. - 2017. - № 10 (1). - P. 277-290.

10. Balat M., Kirtay E., Balat H. Main routes for the thermoconversion of biomass into fuels and chemicals. P. 2: Gasification systems // Energy Conversion and Management. - 2009. № 50 (12). - P. 3158-3168.

11. Autothermal and allothermal pyrolysis in a continuous fixed bed reactor / M. Milhé, L. Van De Steene, M. Haube, W.-F. Fassinou // Journal of Analytical and Applied Pyrolysis. - 2013. - № 103. P. $102-111$.

12. Feasibility of running a micro gas turbine on wood-derived fast pyrolysis bio-oils: Effect of the fuel spray formation and preparation / M. Broumand, M.S. Khan, S. Yun, Z. Hong // Renewable Energy. - 2021. - № 178. - P. 775-784.

13. Experimental investigation of performance and emission characteristics of a miniature gas turbine supplied by blends of бюджета на финансовое обеспечение выполнения государственного задания на оказание государственных услуг (внутренний номер 075-ГЗ/Х4141/687/3).

kerosene and waste tyre pyrolysis oil / T. Suchocki, L. Witanowski, P. Lampart, K. Januszewicz // Energy. - 2021. - V. 215. - P. 119125.

14. Devaraj J., Robinson Y., Ganapathi P. Experimental investigation of performance, emission and combustion characteristics of waste plastic pyrolysis oil blended with diethyl ether used as fuel for diesel engine // Energy. - 2015. - № 85. - P. 304-309.

15. Environmental pollution cost analysis of a diesel engine fueled with biogas-diesel-tire pyrolytic oil blends / N. Tunç, M. Karagöz, B. Çiftçi, E. Deniz // Engineering Science and Technology, an International Journal. - 2021. - № 24 (3). - P. 631-636.

16. Production and utilization of pyrolysis oil from solidplastic wastes: a review on pyrolysis process and influence of reactors design / M. Sekar, V.K. Ponnusamy, A. Pugazhendhi, S. Nižetić // Journal of Environmental Management. - 2022. - № 302. - P. 114046.

17. Sharma A., Murugan S. Combustion analysis of a diesel engine run on non-conventional fuel at different nozzle injection pressure // Lecture Notes in Mechanical Engineering. - 2022. - Part F1. - P. 109-118.

18. Мусабеков М.О., Жаманкулов М.Ж., Мусабекова А.М. Метод исследования влияния новых видов топлив на показатели рабочего процесса ДВС // Вестник Казахской академии транспорта и коммуникаций им. М. Тынышпаева. - 2012. - № 4 (77). - С. 10-16.

19. Турбины тепловых и атомных электростанций / А.Г. Костюк, В.В. Фролов, А.Е. Булкин, А.Д. Трухний. 2-е изд., перераб. и доп. - М.: Изд-во МЭИ, 2001. -488 с

20. Круглов В.И., Султанов В.А., Вареник В.В. Методические указания к выполнению расчетных заданий по курсу Термодинамика и теплопередача. - Казань: Казан. ун-т, 2017. - 46 с.

21. Щипаков В.А., Тарасов А.И. Перспективы использования пульсирующих детонационных технологий в турбореактивных двигателях // Авиационно-космическая техника и технология. - 2011. - № 9 (86). - С. 46-50.

22. Коньков А.Ю., Тимошенко Д.В. Газотурбинные установки для транспорта газа. - Хабаровск: Изд-во Тихооеан. гос. ун-та, 2016. $-151 \mathrm{c}$.

23. Lemmon E.W., Huber M.L., McLinden M.O. Reference fluid thermodynamic and transport properties «REFPROP». 2013. URL: https://www.nist.gov/programs-projects/reference-fluidthermodynamic-and-transport-properties-database-refprop (дата обращения 21.11.2021).

24. Галашов Н.Н., Цибульский С.А. Параметрический анализ схемы парогазовой установки с комбинацией трех циклов для повышения КПД при работе в северных газодобывающих районах // Известия Томского политехнического университета. Инжиниринг георесурсов. - 2019. - Т. 330. - № 5. - С. 44-55.

25. Galashov N.N., Tsibulskii S.A. Thermal efficiency of three-cycle utilization-type steam-gas units // Power Technology and Engineering. - 2015. - № 48 (6) - P. 459-463.

Поступила 13.01.2022 г.

\section{Информация об авторах}

Цибульский С.A., кандидат технических наук, доцент НОЦ И.Н. Бутакова Инженерной школы энергетики Национального исследовательского Томского политехнического университета.

Ларионов К.Б., кандидат технических наук, доцент НОЦ И.Н. Бутакова Инженерной школы энергетики Национального исследовательского Томского политехнического университета.

Слюсарский К.В., кандидат физико-математических наук, доцент НОЦ И.Н. Бутакова Инженерной школы энергетики Национального исследовательского Томского политехнического университета.

Галашов Н.Н., кандидат технических наук, доцент НОЦ И.Н. Бутакова Инженерной школы энергетики Национального исследовательского Томского политехнического университета.

Гаспарян Г.Д., доктор технических наук, профессор, генеральный директор ООО «Сибирский Биоуголь».

Улько А.A., заместитель генерального директора ООО «Сибирский Биоуголь». 
UDC 621.432.3; 621.438.081; 621.438.082

\title{
EVALUATION OF THE EFFICIENCY OF APPLYING WOOD PYROLYSIS STEAM-GAS PRODUCTS AS A WORKING FLUID FOR GAS TURBINE AND INTERNAL COMBUSTION ENGINE
}

\author{
Svyatoslav A. Tsibulskiy', \\ stzibulsky@tpu.ru
}

Kirill B. Larionov1, laryk070@gmail.com

Konstantin V. Slyusarsky ${ }^{1}$ slyuskonst@gmail.com

\section{Nikolay N. Galashov ${ }^{1}$,} gal@tpu.ru

Garik D. Gasparyan², garik.gasparian@yandex.ru

\author{
Alexander A. Ulko², \\ ulkoalexandr@gmail.ru \\ 1 National Research Tomsk Polytechnic University, \\ 30, Lenin avenue, Tomsk, 634050, Russia. \\ 2000 «Sibirskiy Biougol», \\ 33, Voskresenskaya street, Kaluga, 248000, Russia.
}

The relevance of the topic is caused by the possibility of using such energy resource as a steam-gas products of pyrolysis of wood waste as the main or auxiliary fuel for electrical energy generation. These areas associated with a decrease in carbon emissions will allow expanding the scope of pyrolysis as a means of processing industrial waste, minimizing their impact on the environment.

The main aim is to study the issues of increasing the efficiency of electric power generation of internal combustion engines and gas turbine plants working on pyrolysis products of wood waste in order to reduce the consumption of non-renewable energy resources, such as coal, oil and natural gas.

Objects: wood waste pyrolysis unit, internal combustion engines and gas turbine plants operating using steam-gas products of wood waste pyrolysis.

Methods: numerical research methods based on mathematical simulation of systems and elements of internal combustion engines and gas turbine plants based on material and energy balances.

Results. The authors have developed a mathematical model and a simulation program for internal combustion engines and gas turbines burning steam-gas pyrolysis products. A parametric analysis on the influence of the steam-gas products outlet temperature from the pyrolysis plant on the efficiency, electric power and temperature of the exhaust gases of the considered power units was carried out. It was found that for utilization of steam-gas pyrolysis products in order to obtain electrical energy, the most efficient solution is an internal combustion engine operating via Trinkler thermodynamic cycle and a gas turbine unit using according to Brayton thermodynamic cycle, while the absolute electrical efficiency in the nominal operating mode of the pyrolysis unit is 23,34 and $22,28 \%$ respectively. It was found that when using steam-gas pyrolysis products as an auxiliary fuel together with methane with a volumetric fraction of $25 \%$, the decrease in the power of the power unit is expected to be no more than $10 \%$.

\section{Key words:}

Pyrolysis, steam-gas products, thermodynamic cycle, internal combustion engine, gas turbine unit, mathematical model.

The research was financially supported according to the additional agreement no. 075-03-2021-138/3 on aid grant from the Federal budget for financing the fulfillment of the State task in public service delivery (inner no. 075-Г3/X4141/687/3).

\section{REFERENCES}

1. King R., Tingas E.-A. Potential for carbon-neutral advanced biofuels in UK road transport. Journal of Energy Engineering, 2021, vol. 147 (4), pp. 04021025.

2. Jha G., Soren S., Deo K. Mehta Partial substitution of coke breeze with biomass and charcoal in metallurgical sintering. Fuel, 2020, vol. 278, pp. 118350

3. Hoang A.T., Ong H.C., Fattah I.M.R., Sakthivel R. Progress on the lignocellulosic biomass pyrolysis for biofuel production toward environmental sustainability. Fuel Processing Technology, 2021, vol. 223, pp. 106997.

4. Balat M., Kirtay E., Balat H. Main routes for the thermoconversion of biomass into fuels and chemicals. P. 1: Pyrolysis systems. Energy Conversion and Management, 2009, no. 50 (12), pp. 3147-3157.

5. Jahirul M.I., Rasul M.G., Chowdhury M.G., Ashwath N. Biofuels production through biomass pyrolysis - a technological review. Energies, 2012, no. 5 (12), pp. 4952-5001.

6. Larionov K.B., Yankovsky S.A., Gubin V.E., Ulko A.A. Production of briquetted semicoke from wood waste by multistep low-temperature pyrolysis. Coke and Chemistry, 2020, no. 63 (12), pp. 592-598.

7. Oasmaa A., Peacocke C., Gust S., Meier D., McLellan R. Norms and standards for pyrolysis liquids. End-user requirements and specifications. Energy and Fuels, 2005, no. 19 (5), pp. 2155-2163.

8. Kan T., Strezov V., Evans T.J. Lignocellulosic biomass pyrolysis: a review of product properties and effects of pyrolysis parameters. 
Renewable and Sustainable Energy Reviews, 2016, no. 57, pp. 1126-1140.

9. Lange J., Müller F., Bernecker K., Takors R. Valorization of pyrolysis water: a biorefinery side stream, for 1,2-propanediol production with engineered Corynebacterium glutamicum. Biotechnology for Biofuels, 2017, no. 10 (1), pp. 277-290.

10. Balat M., Kirtay E., Balat H. Main routes for the thermoconversion of biomass into fuels and chemicals. P. 2: Gasification systems. Energy Conversion and Management, 2009, no. 50 (12), pp. 3158-3168.

11. Milhé M., Van De Steene L., Haube M., Fassinou W.-F. Autothermal and allothermal pyrolysis in a continuous fixed bed reactor Journal of Analytical and Applied Pyrolysis, 2013, no. 103, pp. 102-111.

12. Broumand M., Khan M.S., Yun S., Hong Z. Feasibility of running a micro gas turbine on wood-derived fast pyrolysis bio-oils: effect of the fuel spray formation and preparation. Renewable Energy, 2021, no. 178, pp. 775-784.

13. Suchocki T., Witanowski L., Lampart P., Januszewicz K. Experimental investigation of performance and emission characteristics of a miniature gas turbine supplied by blends of kerosene and waste tyre pyrolysis oil. Energy, 2021, vol. 215, no. 119125.

14. Devaraj J., Robinson Y., Ganapathi P. Experimental investigation of performance, emission and combustion characteristics of waste plastic pyrolysis oil blended with diethyl ether used as fuel for diesel engine. Energy, 2015, no. 85, pp. 304-309.

15. Tunç N., Karagöz M., Çiftçi B., Deniz E. Environmental pollution cost analysis of a diesel engine fueled with biogas-diesel-tire pyrolytic oil blends. Engineering Science and Technology, an International Journal, 2021, no. 24 (3), pp. 631-636.

16. Sekar M., Ponnusamy V.K., Pugazhendhi A., Nižetić S. Production and utilization of pyrolysis oil from solidplastic wastes: a review on pyrolysis process and influence of reactors design. Journal of Environmental Management, 2022, no. 302, pp. 114046.

17. Sharma A., Murugan S. Combustion analysis of a diesel engine run on non-conventional fuel at different nozzle injection pressure. Lecture Notes in Mechanical Engineering, 2022, P. F1, pp. 109-118.
18. Kruglov V.I., Sultanov V.A., Varenik V.V. Metodicheskie ukazaniya $k$ vypolneniyu raschetnyh zadaniy po kursu Termodinamika $i$ teploperedacha [Methodical instructions for performing settlement tasks at the rate of thermodynamics and heat transfer]. Kazan, Kazan University publ., 2017. 46 p.

19. Kostyuk A.G., Frolov V.V., Bulkin A.E., Trukhniy A.D. Turbiny teplovykh $\mathrm{i}$ atomnykh elektrostantsy [Turbines of thermal and nuclear power plants]. Moscow, MEI Publ., 2001. 488 p.

20. Musabekov M.O., Zhamankulov M.Zh., Musabekova A.M. Metod issledovaniya vliyaniya novykh vidov topliv na pokazateli rabochego protsessa DVS [Method for studying the influence of new types of fuels on the performance of the engine workflow]. Vestnik Kazakhskoy akademii transporta $i$ kommunikatsy im. M. Tynyshpaeva, 2012, no. 4 (77). pp. 10-16.

21. Shchipakov V.A., Tarasov A.I. Perspektivy ispolzovaniya pulsiruyushchikh detonatsionnykh tekhnology $\mathrm{v}$ turboreaktivnykh dvigatelyakh [Prospects for using pulsating detonation technologies in turbojet engines]. Aviatsionno-kosmicheskaya tekhnika $i$ tekhnologiya, 2011, no. 9(86), pp. 46-50.

22. Konkov A.Yu., Timoshenko D.V. Gazoturbinnye ustanovki dlya transporta gaza [Gas turbine gas transportation]. Khabarovsk, Pacific National University publ., 2016. 151 p.

23. Lemmon E.W., Huber M.L., McLinden M.O. Reference fluid thermodynamic and transport properties «REFPROP». 2013. Available at: https://www.nist.gov/programs-projects/referencefluid-thermodynamic-and-transport-properties-database-refprop (accessed 21 November 2021).

24. Galashov N.N., Tsibulskiy S.A. Parametric analysis of the diagram of the combined cycle gas turbine with a combination of three cycles for improving efficiency when operating in northern gas producing areas. Bulletin of the Tomsk Polytechnic University. Geo Assets Engineering, 2019, vol. 330, no. 5, pp. 44-55. In Rus.

25. Galashov N.N., Tsibulskii S.A. Thermal Efficiency of Three-Cycle Utilization-Type Steam-Gas Units. Power Technology and Engineering, 2015, no. 48 (6), pp. 459-463.

Received: 13 January 2022.

Information about the authors

Svyatoslav A. Tsibulskiy, Cand. Sc., associate professor, National Research Tomsk Polytechnic University.

Nikolay N. Galashov, Cand. Sc., associate professor, National Research Tomsk Polytechnic University.

Kirill B. Larionov, Cand. Sc., associate professor, National Research Tomsk Polytechnic University.

Konstantin V. Slyusarsky, Cand. Sc., associate professor, National Research Tomsk Polytechnic University.

Garik D. Gasparyan, Dr. Sc., professor, chief executive manager, LTD «Sibirskiy Biougol»

Alexander A. Ulko, vice manager, LTD «Sibirskiy Biougol». 